\title{
Structural, elastic, electronic and thermal properties of InAs: A study of functional density
}

\author{
Propiedades estructurales, elásticas, electrónicas y térmicas del lnAs: \\ Un estudio de densidad funcional
}

Propriedades estruturais, elásticas, eletrônicas e térmicas do InAs: Um estudo de densidade funcional

Fecha de recepción: 13 de octubre de 2016

Fecha de aceptación: 1 de julio de 2017

\author{
Víctor Mendoza-Estrada* \\ Melissa Romero-Baños ${ }^{* *}$ \\ Viviana Dovale-Farelo** \\ William López-Pérez $z^{\text {t*to }}$ \\ Álvaro González-García***** \\ Rafael González-Hernández ${ }^{* * *+*}$
}

\begin{abstract}
In this research, first-principles calculations were carried out within the density functional theory (DFT) framework, using LDA and GGA, in order to study the structural, elastic, electronic and thermal properties of InAs in the zincblende structure. The results of the structural properties $\left(a, B_{0}, B^{\prime}{ }_{0}\right)$ agree with the theoretical and experimental results reported by other authors. Additionally, the elastic properties, the elastic constants $\left(C_{11}, C_{12}\right.$ and $\left.C_{44}\right)$, the anisotropy coefficient $(A)$ and the predicted speeds of the sound $\left(V_{l}, V_{s 1}\right.$, and $\left.V_{s 2}\right)$ are in agreement with the results reported by other authors. In contrast, the shear modulus $(G)$, the Young's modulus $(Y)$ and the Poisson's ratio (v) show some discrepancy with respect to the experimental values, although, the values obtained are reasonable. On the other hand, it is evident the tendency of the LDA and GGA approaches to underestimate the value of the band-gap energy in semiconductors. The thermal properties $\left(\mathrm{V}, B_{0}, \theta_{\mathrm{D}}\right.$ y $\left.\mathrm{C}_{\mathrm{V}}\right)$ of InAs, calculated using the quasiharmonic Debye model, are slightly sensitive as the temperature increases. According to the stability criteria and the negative value of the enthalpy of formation, InAs is mechanically and thermodynamically stable. Therefore, this work can be used as a future reference for theoretical and experimental studies based on InAs.
\end{abstract}

Keywords: Density functional theory; InAs; Semiconductors; Structural parameter; Thermal properties.

\footnotetext{
* M. Sc. Universidad del Norte; Universidad de la Costa (Barranquilla-Atlántico, Colombia). evictor@uninorte.edu.co; vmendoza@cuc.edu.co.

** M.Sc. Universidad del Norte; Universidad de la Costa (Barranquilla-Atlántico, Colombia). melissabanos@uninorte.edu.co; mromero@cuc.edu.co.

*** M.Sc. Universidad del Norte (Barranquilla-Atlántico, Colombia). vdovale@uninorte.edu.co.

**** Ph.D. Universidad del Norte (Barranquilla-Atlántico, Colombia).wlopez@uninorte.edu.co.

***** M.Sc. Universidad del Norte (Barranquilla-Atlántico, Colombia). alvarogonzalez@uninorte.edu.co. ORCID: 0000-0002-8789-0960.

****** Ph.D. Universidad del Norte (Barranquilla-Atlántico, Colombia).rhernandezj@uninorte.edu.co.
} 


\section{Resumen}

En esta investigación se realizaron cálculos de primeros principios en el marco de la teoría del funcional de la densidad (DFT), utilizando las aproximaciones LDA y GGA, con el fin de estudiar las propiedades estructurales, elásticas, electrónicas y térmicas del InAs en la estructura zinc blenda. Los resultados de las propiedades estructurales $\left(a, B_{0}, B^{\prime}{ }_{0}\right)$ muestran un buen acuerdo con los resultados teóricos y experimentales reportados por otros autores. Con respecto a las propiedades elásticas, las constates elásticas $\left(C_{11}, C_{12}\right.$ y $\left.C_{44}\right)$, el coeficiente de anisotropía $(A)$ y las velocidades del sonido $\left(V_{l}, V_{s 1}\right.$ y $\left.V_{S 2}\right)$ predichas están acordes con los resultados reportados por otros autores. En contraste, el módulo de Shear $(G)$, el módulo de Young $(Y)$ y la razón de Poisson $(v)$ presentan cierta discrepancia con respecto a los valores experimentales; sin embargo, los valores obtenidos son razonables. Por otro lado, se evidencia la tendencia de las aproximaciones LDA y GGA a subestimar el valor de la brecha de energía prohibida en los semiconductores. Las propiedades térmicas $\left(\mathrm{V}, B_{0}, \theta_{\mathrm{D}}\right.$ y $\left.\mathrm{C}_{\mathrm{V}}\right)$ del InAs, calculadas usando el modelo cuasi-armónico de Debye, son ligeramente sensibles a medida que aumenta la temperatura. De acuerdo con los criterios de estabilidad y el valor negativo de la entalpia de formación, el InAs es mecánicamente y termodinámicamente estable. Por lo tanto, este trabajo puede ser utilizado como referencia para estudios teóricos y experimentales basados en InAs.

Palabras clave: InAs; Parámetros estructurales; Propiedades térmicas; Semiconductores; Teoría del funcional de la densidad.

\section{Resumo}

Nesta pesquisa realizaram-se cálculos de primeiros princípios no marco da teoria do funcional da densidade (DFT), utilizando as aproximações LDA e GGA, com o intuito de estudar as propriedades estruturais, elásticas, eletrônicas e térmicas do InAs na estrutura zinco blenda. Os resultados das propriedades estruturais $\left(a, B_{0}, B^{\prime}{ }_{0}\right)$ mostram um bom ajuste com os resultados teóricos e experimentais reportados por outros autores. Com respeito às propriedades elásticas, as constantes elásticas $\left(C_{11}, C_{12}\right.$ e $\left.C_{44}\right)$, o coeficiente de anisotropia $(A)$ e as velocidades do som $\left(V_{s}, V_{s 1}\right.$ e $\left.B_{0}\right)$ preditas estão de acordo com os resultados reportados por outros autores. Em contraste, o módulo de Shear $(G)$, o módulo de Young $(Y)$ e a razão de Poisson $(v)$ apresentam certa discrepância com respeito aos valores experimentais; porém, os valores obtidos são razoáveis. Por outro lado, evidencia-se a tendência das aproximações LDA e GGA a subestimar o valor da brecha de energia proibida nos semicondutores. As propriedades térmicas $\left(\mathrm{V}, B_{0}, \theta_{\mathrm{D}}\right.$ e $\left.\mathrm{C}_{\mathrm{V}}\right)$ do $\operatorname{InAs}$, calculadas usando o modelo quase-harmônico de Debye, são ligeiramente sensíveis a medida que aumenta a temperatura. De acordo com os critérios de estabilidade e o valor negativo da entalpia de formação, o InAs é mecanicamente e termodinamicamente estável. Portanto, este trabalho pode ser utilizado como referência para estudos teóricos e experimentais baseados em InAs.

Palavras chave: InAs; Teoria do funcional da densidade; Semicondutores; Parâmetros estruturais; Propriedades térmicas. 


\section{INTRODUCTION}

Indium arsenide (InAs) is a group III-V semiconductor compound with high electron mobility and a narrow direct band-gap. Under normal conditions, it crystallizes into a cubic zinc-blende structure [1], with a lattice parameter $a=6.058 \AA[2,3]$. This compound has been extensively studied because it provides a good basis for many commercial applications and new technologies, established in electronic and optoelectronic devices, such as light emitting diodes, photodetectors and lasers [4, 5]. The operating characteristics of these electronic and optoelectronic devices depend not only on the materials engineering at a practical level, but also on a clear understanding of the material's properties and the fundamental science behind them. Therefore, theoretical and experimental investigations of the mechanical properties of the crystal, such as elastic constants $\left(C_{11}, C_{12}\right.$ and $\left.C_{44}\right)$, and the elastic properties derived from them - anisotropy coefficient $(A)$, volumetric modulus $\left(B_{0}\right)$, shear modulus $(G)$, Young's modulus $(Y)$ and Poisson's ratio $(v)$ - are very important because they relate to several fundamental solid-state phenomena such as interatomic potentials and state equations [6-11]. These elastic properties are also thermally related to the Debye temperature and the specific heat of InAs. Due to its technological importance, it is paramount to know the different properties of InAs; therefore, in this paper, we present the its structural, elastic, electronic and thermal properties, using the total energy calculation approach of the fundamental state of the system. These results provide a fundamental basis for understanding the physical properties of the InAs compound. All of the properties mentioned above were calculated using the local density approximation (LDA) and the generalized gradient approximation (GGA).

\section{Computational MEthods}

For the study and analysis of the structural, elastic and electronic properties of InAs, ab initio calculations were performed using the pseudo-potential method within the density functional theory (DFT) framework. The effects of exchange and correlation were tested with the local density approximation (LDA) [12] and the generalized gradient approximation (GGA), with the Perdew-Burke-Ernzerhof functional (PBE) [13]. Core electrons were described by the projector augmented wave method (PAW) $[14,15]$, in which the $4 d$ state of $I n$ and the $3 d$ state of $A s$ were included as valence electrons. The computational code of the Vienna Ab Initio Simulation Package (VASP) was used [16, 17]. The electronic wave function was expanded in plane waves up to a cutoff energy of 520 $\mathrm{eV}$. A gamma-centered grid of $8 \times 8 \times 8 k$-point was used to sample the irreducible Brillouin zone. For the pseudo-potentials of $I n$ and $A s$, the valence electrons in the states $5 s^{2} 4 d^{10} 5 p^{1}$ and $4 s^{2} 3 d^{10} 4 p^{3}$, respectively, were considered. The thermal effects were analyzed using the quasi-harmonic Debye model, implemented in the Gibbs 2 code [18]. The Gibbs 2 program requires energy-volume data obtained from first-principles calculations to obtain the Gibbs Free Energy G (V, P, $\mathrm{T})$ and minimize $\mathrm{G}$ to establish the thermal EOS V (P, T). Details of this procedure were shown by the Code Developers $[18,19]$.

\section{RESULTS AND DISCUSSION}

\section{A. Structural properties}

Fig. 1 shows the zinc-blende structure (ZB) of InAs. The unit cell consists of four In atoms and four $A s$ atoms and can be described by the lattice parameter $a$. In this structure, the anions of $A s$ are coordinated to four cations of $I n$, forming $\mathrm{AsIn}_{4}$ tetrahedra with four $A s-I n$ bonds, each In atom is shared by the four nearest tetrahedra.

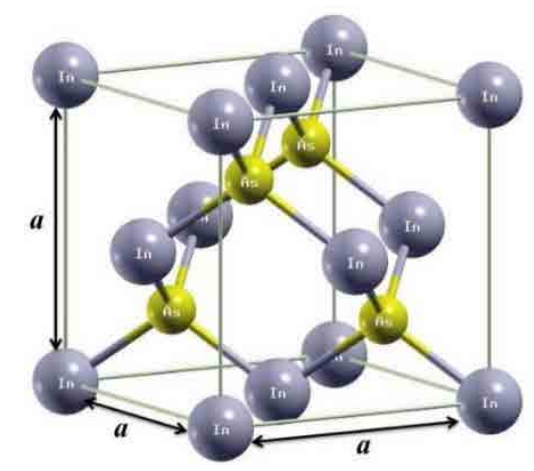

Fig. 1. Cubic zinc-blende structure of InAs, unit cell.

In order to study the structural properties of $\operatorname{InAs}$, we initially calculated the total energy of the conventional cell at different volumes, decreasing and increasing the experimental lattice parameter from -2.5 to 2.5 $\%[2,3]$ along the three perpendicular axes. The total energy versus volume curve shown in Fig. 2 was fitted to the Murnaghan equation of state [20]: 


$$
E(V)=E_{0}+\frac{B_{0} V}{B_{0}^{\prime}}\left[\frac{\left(V_{0} / V\right)^{B^{\prime}}}{B_{0}-1}+1\right]-\frac{B_{0} V_{0}}{B^{\prime}{ }_{0}-1}
$$

Where $B_{0}$ is the volumetric modulus, $B^{\prime}{ }_{0}$ is its first derivative with respect to pressure, $V_{0}$ is the equilibrium volume at zero temperature, and $E_{0}$ is the equilibrium energy of the structure. The difference of the equilibrium energy of the LDA and GGA approximations is defined as: $\Delta \mathrm{E}=\mathrm{E}_{\mathrm{LDA}}-\mathrm{E}_{\mathrm{GGA}}$, if $\Delta \mathrm{E}$ is negative, the LDA predicts the most stable structure; otherwise, if positive, the structure is more stable with the GGA. The calculated value for $\Delta \mathrm{E}$ was approximately $-5.20 \mathrm{eV}$, which indicates high structure stability with LDA.

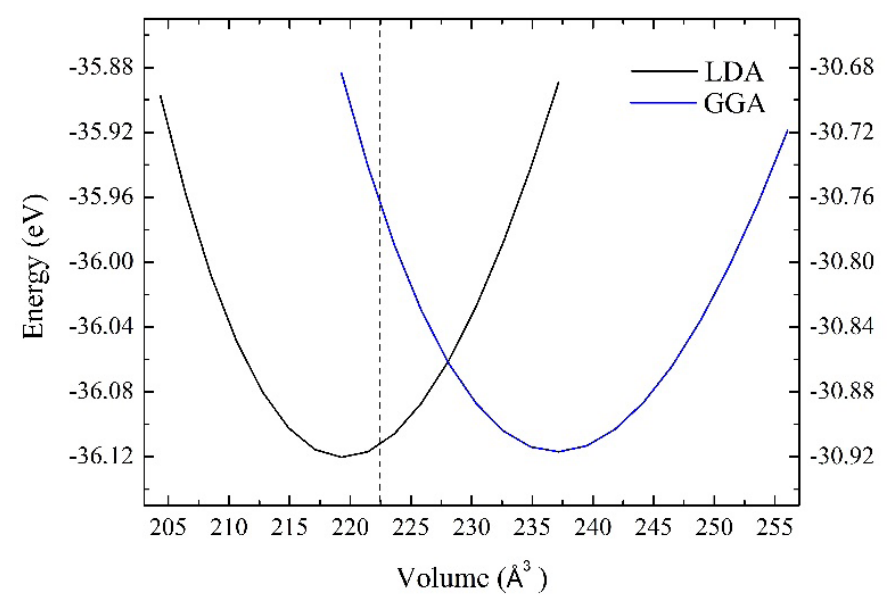

Fig. 2. Energy versus volume of InAs calculated with LDA and GGA. The experimental equilibrium volume is indicated by the vertical discontinuous line.

The lattice parameters, volumetric modulus and its derivative for the LDA and GGA are presented in Table 1, next to their respective experimental and theoretical results as reported by other authors. In this table, it can be seen that the values obtained by this research for the structural parameters $\left(a, B_{0}, B^{\prime}{ }_{0}\right.$ ) approximate the theoretical [3] and experimental values previously reported $[2,3,5,21,22]$. The LDA tends to underestimate the value of the lattice parameter $a$ by $0.44 \%$ with respect to the experimental value; while it overestimates the volumetric modulus by $3.42 \%$. In contrast to the LDA, the GGA corrects the underestimation of the lattice parameter and the overestimation of the volumetric module; however, it tends to overestimate and underestimate these values by $\sim 2.14 \%$ and $\sim 16.65 \%$ respectively. The values gathered from the derivative of the volumetric module are consistent with those reported experimentally and theoretically in the literature. The LDA tends to provide results that are closer to those reported experimentally, predicting more accurately the calculation of the structural parameters.

On the other hand, the cohesive energy $\left(E_{c o h}\right)$ (by cation-anion pair) of InAs was determined using relation (2), where $E_{T}^{I n A s}$ is the total energy per each cation-anion pair of the InAs compound, $E_{T}^{I n}$ and $E_{T}^{A s}$ are the energies of the isolated atoms of $I n$ and $A s$, respectively.

$$
E_{c o h}=E_{T}^{I n A s}-E_{T}^{I n}-E_{T}^{A s}
$$

Table 1 shows that the results obtained for the cohesive energy with the LDA and the GGA are in agreement with those reported theoretically when using the same functional $[3,7]$; however, it shows some discrepancy with the experimental results $[3,5]$. This is due to the LDA and GGA limitations to reproduce the bonding energies between atoms, which are significantly underestimated.

In order to study the stability of InAs, the enthalpy of formation $\left(\Delta H_{f}\right)$ (per cation-anion pair) was calculated using formula (3), where $E_{T}^{I n-v o l}$ and $E_{T}^{A s-v o l}$ are the energies of the atoms of $I n$ and $A s$ determined in their cells. A positive (negative) value of $\Delta H_{f}$ represents an endothermic (exothermic) reaction. The InAs is a thermodynamically stable structure because it exhibits 
negative values of $\Delta H_{f}$ with both the LDA and the GGA approaches (Table 1), which agrees with the theoretical [7] and experimental [23] results reported in the literature.

$$
\Delta H_{f}=E_{T}^{I n A s}-E_{T}^{I n-v o l}-E_{T}^{A s-v o l}
$$

\section{B. Elastic properties}

The three independent elastic constants of the InAs $\left(C_{11}, C_{12}\right.$ and $\left.C_{44}\right)$ define the mechanical stability of the material, and are usually derived from the total energy calculations, representing the elastic properties of the crystal. The stability conditions for the cubic crystals are defined by (4).

$$
C_{11}-C_{12}>0, C_{11}+2 C_{12}>0 \mathrm{y} C_{44}>0
$$

The first condition is equivalent to $C_{11}>\left|C_{12}\right|$, and the first two imply that $C_{I l}>0$. The values of the elastic constants calculated with the LDA and the GGA (Table 1) satisfy these stability conditions. Therefore, the zinc-blende structure of the InAs is mechanically stable. When analyzing the results obtained using the two approximations, the sequence $C_{11}>C_{12}>C_{44}$ is observed; this values are in line with those obtained experimentally [6] and theoretically [7, 8]. However, the LDA (GGA) overestimates (underestimate) the experimental values of $C_{11}$ and $C_{12}\left(C_{11}, C_{12}\right.$ and $\left.C_{44}\right)$, while underestimating the value of $C_{44}$.

From the results of the elastic constants, the anisotropy coefficient $A$ of the InAs was determined using the relation (5) [24], which represents a measure of the anisotropy of the crystal. A perfectly isotropic material is one for which $A$ has a value of 1 , therefore, values smaller or greater than the unity represent a degree of anisotropy in the crystal. The calculated values for $A$ were 0.48 for the LDA and 0.5 for the GGA, therefore, InAs is not perfectly isotropic in its elastic properties, which agrees with Ellaway et al. [9] and Louail et al. [10]. These authors found that $A$ is pressure independent and equal to 0.5 in the zinc-blende phase of the InAs.

$$
A=\frac{C_{11}-C_{12}}{2 C_{44}}
$$

If the aim is to calculate the isotropic elastic properties for polycrystalline materials, such as volumetric modulus $\left(B_{0}\right)$, shear modulus $(G)$, Young's modulus $(Y)$, and Poisson's ratio $(v)$, when using the elastic constants of an anisotropic crystal, the averaged methods of Voigt-Reuss-Hill [25-28] are useful. For cubic systems, the volumetric modulus $\left(B_{0}\right)$ is the same for the averaged methods of Voigt and Reuss and is given by equation (6) [25-28]:

$$
B_{0}=\frac{1}{3}\left(C_{11}+2 C_{12}\right)
$$

The calculated value of $B_{0}$ from the elastic constants had almost the same value as the one obtained from the adjustment of the Murnaghan equation of state (Table 1), which can be a good indicator of the reliability and accuracy of the elastic constants calculated for the InAs.

With the Voigt method, the shear modulus $(G)$ in the cubic system is calculated using relation (7) [25-28], which provides maximum theoretical values for the shear modulus; whereas the Reuss method, given by (8) [25-28], obtains minimum theoretical values.

$$
\begin{gathered}
G_{V}=\frac{C_{11}-C_{12}+3 C_{44}}{5} \\
G_{R}=\frac{5\left(C_{11}-C_{12}\right) C_{44}}{4 C_{44}+3\left(C_{11}-C_{12}\right)}
\end{gathered}
$$

Generally, the arithmetic mean, $G=\left(G_{V}+G_{R}\right) / 2$, is taken as the estimate of the shear modulus; hence the value of $G$ must be between those of Voigt and Reuss [26].

The Young's modulus $(Y)$ and Poisson's ratio $(v)$ can be expressed by (9) and (10) respectively.

$$
\begin{gathered}
Y=\frac{9 G B_{0}}{3 B_{0}+G} \\
v=\frac{3 B_{0}-2 G}{2\left(3 B_{0}+G\right)}
\end{gathered}
$$

The shear modulus $(G)$, the Young's modulus $(Y)$, and the Poisson's ratio $(v)$ are important for engineering and technological applications. The first two provide a measure of the rigidity of the solid, that is, the higher the values of $G$ and $Y$, the more rigid the material. The Poisson's ratio $(v)$ is a measure of the 
crystal's shear strength and provides information about the characteristics of the binding forces. Values of $v$ between 0.25 and 0.50 are given for solids with central forces [26]. The calculated values of the shear modulus $(G)$, the Young's modulus $(Y)$ and the Poisson's ratio $(v)$ are presented in Table 1, next to their respective theoretical [7] and experimental results [11]. The predicted values of $v$ are close to 0.3 , indicating that the interatomic forces in the InAs are predominantly central forces. In this table, it can be observed that the values of the elastic properties mentioned above present some discrepancy with the experimental values. Similar results were reported by
Uesugi et al. [25] when studying the elastic properties of AlLi. These authors assume that this behavior is due to the sensitivity of the elastic properties (except the volumetric modulus) of the actual polycrystalline materials, to the number of grains, and to the texture of the material. This was demonstrated experimentally by Kuriyama et al. $[29,30]$ by determining the Young's modulus of InLi. These authors showed that its value varied from $38.75 \mathrm{GPa}$ to $67.8 \mathrm{GPa}$, which is about 75 $\%$ different; therefore, in the theoretical calculations, where elastic properties of monocrystalline crystals are predicted, this type of disagreement with the experiment is expected.

\section{TABLE 1}

LATTICE PARAMETER (A $(\AA))$, COHESIVE ENERGY $($ ECOH) AND ENTHALPY OF FORMATION $(\Delta \mathrm{HF})$ (PER CATION-ANION PAIR), ELASTIC CONSTANTS (C11, C12 Y C44), VOLUMETRIC MODULUS B0 AND ITS Derivative B'0 Shear modulus (G), Young's modulus (Y), Poisson's Ratio (v), SPEED of A LONGITUDINAL WAVE IN THE DIRECTION [110] $\left(V_{l}\right)$, SPEED OF A POLARIZED SHEAR WAVE IN THE DIRECTION [001] $\left(V_{s 1}\right)$, SPEED OF A POLARIZED SHEAR WAVE IN THE DIRECTION [1 1110$]\left(V_{s 2}\right)$ AND BAND-GAP ENERGY EGAP FOR INAs, CALCULATED WITH LDA AND GGA.

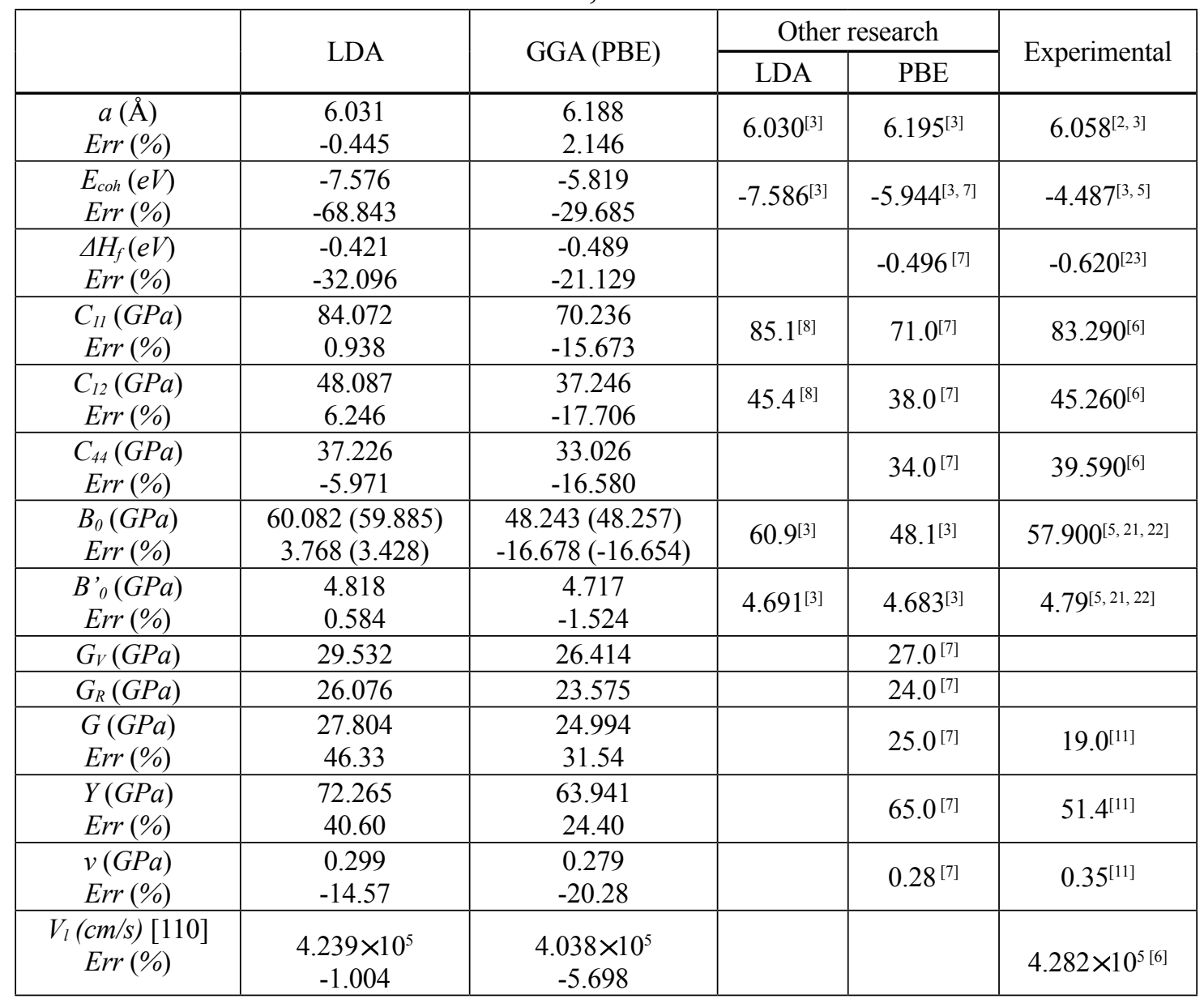


Álvaro González-García - Rafael González-Hernández

\begin{tabular}{|c|c|c|c|c|c|}
\hline & \multirow{2}{*}{ LDA } & \multirow{2}{*}{ GGA $(\mathrm{PBE})$} & \multicolumn{2}{|c|}{ Other research } & \multirow{2}{*}{ Experimental } \\
\cline { 4 - 5 } & & LDA & PBE & \\
\hline $\begin{array}{c}V_{s 1}(\mathrm{~cm} / \mathrm{s})[001] \\
\operatorname{Err}(\%)\end{array}$ & $\begin{array}{c}2.545 \times 10^{5} \\
-3.817\end{array}$ & $\begin{array}{c}2.491 \times 10^{5} \\
-5.857\end{array}$ & & & \multirow{2}{*}{$2.646 \times 10^{5[6]}$} \\
\hline $\begin{array}{c}V_{s 2}(\mathrm{~cm} / \mathrm{s})[1 \overline{1} 110] \\
E r r(\%)\end{array}$ & $\begin{array}{c}1.769 \times 10^{5} \\
-3.333\end{array}$ & $\begin{array}{c}1.760 \times 10^{5} \\
-3.825\end{array}$ & & & \\
\hline$E_{\text {gap }}(\mathrm{eV})$ & 0.00 & 0.00 & $0.00^{[3]}$ & $0.00^{[3]}$ & $0.418^{[5]}$ \\
\hline
\end{tabular}

Due to the anisotropy of the InAs, the speed of sound in this material strongly depend on the direction of propagation. If the density $(\rho)$ and elastic constants $\left(C_{11}, C_{12}\right.$ and $\left.C_{44}\right)$ of the cubic crystal are known, three independent speeds of sound can be calculated through relations (11-13) [31].

$$
\begin{gathered}
V_{l}=\left[\frac{\left(C_{11}+C_{12}+2 C_{44}\right)}{2 \rho}\right]^{\frac{1}{2}} \\
V_{s 1}=\left[\frac{\left(C_{44}\right)}{\rho}\right]^{\frac{1}{2}} \\
V_{s 2}=\left[\frac{\left(C_{11}-C_{12}\right)}{2 \rho}\right]^{\frac{1}{2}}
\end{gathered}
$$

Where $V_{l} V_{l}$ is the speed of a longitudinal wave in the direction[110], $V_{S 1} V_{s 1}$ is the speed of a polarized shear wave in the direction [001], and $V_{s 2} V_{s 2}$ is the velocity of a polarized shear wave in the direction [110]. The values for $\rho$ were calculated with the $\operatorname{LDA}(5,747 \mathrm{~g} /$ $\left.\mathrm{cm}^{3}\right)$ and the GGA $\left(5,320 \mathrm{~g} / \mathrm{cm}^{3}\right)$; these results concur with the experimental value $\left(5,680 \mathrm{~g} / \mathrm{cm}^{3}\right)$ reported by other authors [32]. Table 1 presents the speeds of sound in the different directions of propagation along with their respective error percentages for each approximation with respect to the experimental values [6]. The comparison between our calculations and the experiment indicates that the computational approach used to determine the vibrational properties of the system gives results consistent with the experimental values.

\section{Electronic properties}

Fig. 3 shows the partial states density of the InAs for each atomic orbital of the constituent elements, calculated with the LDA and the GGA. The zero energy has been placed at the Fermi level; below this level, the valence band (BV) is found between the energy range of $-6 \mathrm{eV}$ to $0 \mathrm{eV}$, formed with a higher contribution by electrons of the $4 p-A s$ states; the electrons of the $5 p$-In and $4 d$-In states have a lower contribution. The symmetrical distributions between the majority and minority spin regions show a nonmagnetic behavior in the InAs.
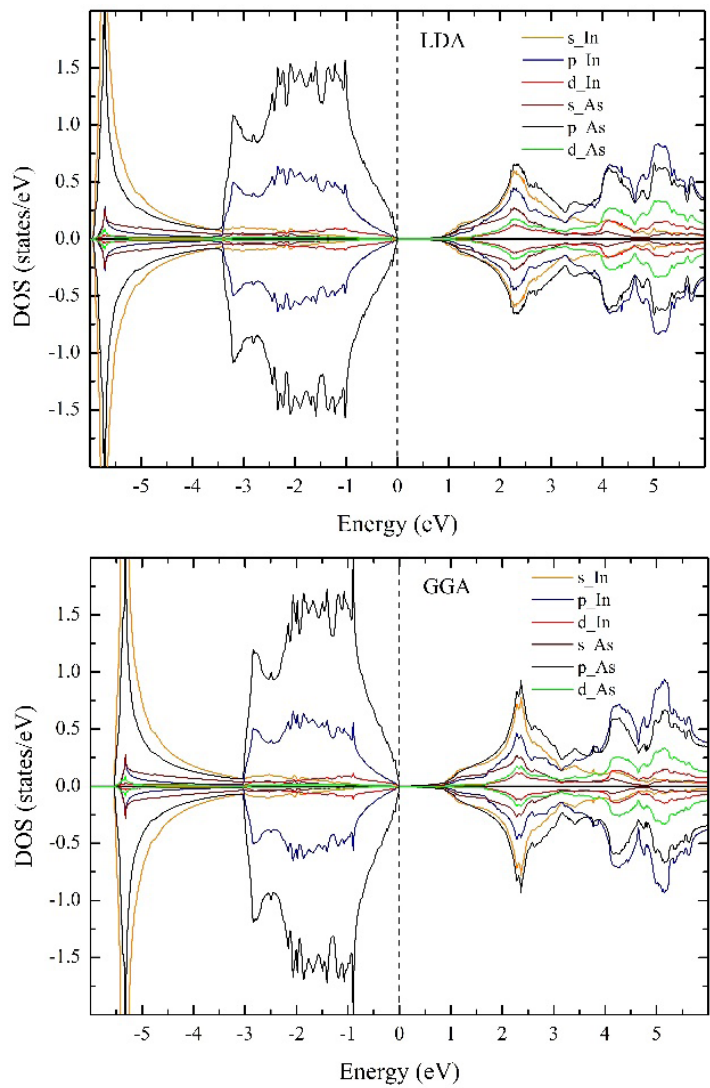

Fig. 3. Density of the partial states of the InAs compound, obtained with LDA (left) and GGA (right).

The vertical discontinuous line indicates the Fermi level, which has been reduced to zero.

The calculated lattice parameter $(a)$ is largely determined by the energy levels or layers of the outermost valence electrons. When the density of a state is calculated with the LDA, within the valence 
band, the states move toward lower energies and the orbitals near the Fermi level decrease considerably in height with respect to the band orbitals calculated with the GGA (Fig. 3), which could explain the decrease in the LDA lattice parameter in comparison to the GGA. Therefore, since the lattice parameter $(a)$ in the LDA is of less value than in the GGA, the binding energy of the states of the valence electrons is overestimated, amplifying the coupling effects of the $4 p-A s$ and $5 p$ In orbitals. As a consequence of this strong coupling, there is an increase in the elastic properties obtained with the LDA when compared to the GGA (Table 1).

The conduction band (BC) is located above the Fermi level, and it receives a greater contribution from the $4 p$ $A s$ and $4 s$-In electrons and a smaller contribution from the other orbitals. The band-gap energy $\left(E_{g a p}\right)$ is due to the interaction between the electrons that dominate the lower part of the conduction band and the electrons that dominate the upper part of the valence band, and its value was predicted by the aforementioned approximations (Table 1), which shows the tendency of the LDA and the GGA to underestimate the value of the band-gap energy in the semiconductors. Therefore, in figure 3 , it is not possible to observe the semiconductor character of the InAs. Nevertheless, the Tran-Blaha-modified Becke-Johnson (TB-mBJ) potential [33] was used to correct the band-gap energy. TB-mBJ potential can give larger band-gap energy values than PBE or LDA functional, due to the fact that TB-mBJ is strictly an exchange-correlation potential. The band-gap energy value obtained is $0.28 \mathrm{eV}$, which is closer to the experimental data $(0.418 \mathrm{eV})$ [5].

\section{Thermal properties}

The thermal properties of the InAs were calculated using the quasi-harmonic Debye model, in a temperature range from 0 to $1650 \mathrm{~K}$, where this model is completely valid. In order to determine the thermal behavior of the compound, first-principles calculations were initially performed with the LDA and the GGA to obtain the energy-volume data, which are the inputs to the Gibbs 2 program. Recently, the Gibbs 2 code was used to study the thermal behavior of the compounds $\mathrm{CSi}_{2} \mathrm{~N}_{4}$ and $\mathrm{SC}_{x} Y_{1-x}[34,35]$.

Figure 4 shows the volume $(V)$, the volumetric modulus $\left(B_{0}\right)$, the Debye temperature $\left(\theta_{\mathrm{D}}\right)$ and the heat capacity at constant volume $\left(C_{V}\right)$ as a function of the temperature and at $0 \mathrm{GPa}$ of the InAs, calculated with the entry data from the LDA and the GGA. In this figure, it can be observed that the volume (volumetric module) for each approximation increases (decreases) with an increase in temperature. However, it can be noted that the volume (volumetric modulus) is almost constant from 0 to $100 \mathrm{~K}$ and has a nonlinear increase (decreases) with the temperature for $\mathrm{T}>100 \mathrm{~K}$. It should be highlighted that the LDA (GGA) maintains the tendency to underestimate and overestimate (overestimate and underestimate) the volume and volumetric modulus, respectively, with the increase in temperature. On the other hand, the Debye temperature as a function of temperature and at 0 GPa remains unchanged with the increase in temperature in the range of 0 to about $100 \mathrm{~K}$ (Fig. 4c). When $\mathrm{T}>$ $100 \mathrm{~K}$, the magnitude of $\theta_{\mathrm{D}}$ decreases non-linearly, indicating the change in the vibration frequency of the particles with the temperature. Since $\theta_{\mathrm{D}}$ is associated with the maximum crystal vibration frequency $\left(\omega_{D}\right)$, according to relation (14) [36], it is expected for $\omega_{D}$ to be related to the oscillation frequencies of the InAs atoms, whose vibration frequencies are associated with the bonding forces, which in turn are related to the elastic properties, in particular with $B_{0}$. Therefore, in observing the behavior of $B_{0}$ with the temperature (Fig. 4b), a similar behavior was expected for $\theta_{\mathrm{D}}$ with a higher and near constant value at low temperatures $(\mathrm{T}<100 \mathrm{~K})$, due to the rigidity of InAs within this temperature range; and lower at high temperatures $\left(\sim 1670 \mathrm{~K}\right.$ for LDA and $\sim 1150 \mathrm{~K}$ for PBE) where $B_{0}$ tends to zero, implying that the material is softer.

$$
\theta_{D}=\frac{\hbar \omega_{D}}{k_{B}}
$$



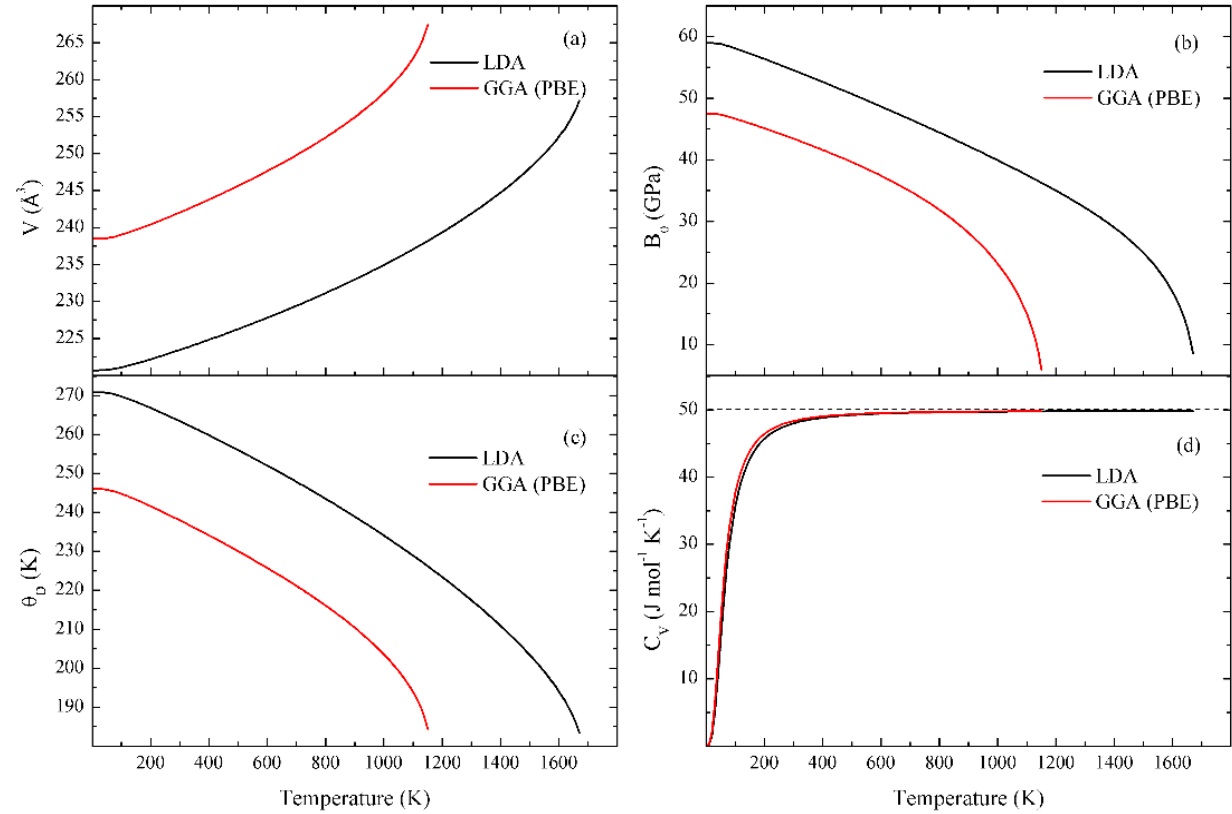

Fig. 4. Volume $(\mathrm{V})$, volumetric modulus $\left(B_{0}\right)$, Debye temperature $\left(\theta_{\mathrm{D}}\right)$ and heat capacity at constant volume $\left(\mathrm{C}_{\mathrm{V}}\right)$ as a function of temperature and at $0 \mathrm{GPa}$ of the InAs.

The heat capacity at constant volume is another essential parameter used to describe the thermal properties of the InAs. At $\mathrm{T}=0 \mathrm{~K}$, the heat capacity tends to zero, and at low temperatures, it increases with $\mathrm{T}^{3}$ to approximately $200 \mathrm{~K}$, due to the inharmonic approximation of the Debye model; then it gradually increases with the increase in temperature and converges to the constant limits of the Dulong-Petit law, where it does not depend on temperature (Fig. 4d). This is common for all solids at high temperatures.

\section{Conclusions}

In the present research the structural, elastic, electronic and thermal properties of the InAs compound in its zinc-blende (ZB) phase were studied from firstprinciples calculations. Regarding the results of the structural parameters $a, B_{0}$ and $B_{0}^{\prime}$, the LDA and the GGA generally agreed with the experimental data; however, the LDA tended to underestimate the value of the lattice parameter $a$, while overestimating the volumetric modulus and its derivative. On the other hand, the GGA approximation, even though corrected the underestimation (overestimation) of the lattice parameter $a$ (volumetric module and its derivative), it tended to overestimate (underestimate) that value.
With respect to the elastic properties, the predicted elastic tests $\left(C_{11}, C_{12}\right.$ and $\left.C_{44}\right)$ were in line with those obtained experimentally and theoretically. Nevertheless, the shear modulus $(G)$, the Young's modulus $(Y)$ and the Poisson's ratio $(v)$ showed some discrepancy with respect to the experimental values, although the obtained values were reasonable. The results obtained for the thermal properties with the Gibbs 2 code, from the energy-volume data of the LDA and the GGA, showed that the volume $(V)$, the volumetric modulus $\left(B_{0}\right)$, the Debye temperature $\left(\theta_{\mathrm{D}}\right)$ and the heat capacity at constant volume $\left(C_{V}\right)$ are slightly sensitive as the temperature increases. According to the stability criteria and the negative value of the enthalpy of formation, the InAs is mechanically and thermodynamically stable. This work can be used as a future reference for theoretical and experimental studies based on InAs, since it covers the lack of data resulting from the few published reports on the thermal properties of this compound.

\section{ACKNOWLedgements}

This work has been carried out with the financial support of Universidad del Norte and Colciencias (Administrative Department of Science, Technology and Research of Colombia) under "Convocatoria 712- 
2015 (Convocatoria para proyectos de investigación en ciencias básicas año 2015)." The calculations reported in this paper were performed using the machines of the computational laboratory at the Universidad del Norte. The authors thank DIDI office for their useful management in the project.

\section{REFERENCES}

[1] A. Mujica, A. Rubio, A. Muñoz, and R. J. Needs, "High-pressure phases of group-IV, III-V, and IIVI compounds," Rev. Mod. Phys, vol. 75 (3), pp. 863-912, Jul. 2003. DOI: http://doi.org/10.1103/ RevModPhys.75.863.

[2] K. Seung-Hwan, and S. L. Sheng, "Theoretical investigation of $\mathrm{InAs} / \mathrm{GaInSb}$ type-II superlattice infrared detectors for longwavelength and very longwavelength infrared applications," Physica E., vol. 16 (2), pp. 199-208, Feb. 2003. DOI: http://doi. org/10.1016/S1386-9477(02)00667-7.

[3] R. Ahmed, S. J. Hashemifar, H. Akbarzadeh, M. Ahmed, and Fazal-e-Aleem, "Ab initio study of structural and electronic properties of III-arsenide binary compounds," Comp Mat Sci, vol. 39 (3), pp. 580-586, May. 2007. DOI: http://doi.org/10.1016/j. commatsci.2006.08.014.

[4] D. R. Lide, Handbook of Chemistry and Physics, Boca Raton FL: CRC Press, 87th ed, 1998.

[5] Landolt-Börnstein, "Semiconductors, Physics of Group IV Elements and III-V Compounds," New Series, Group III, vol. 17, edited by O. Madelung, M. Schulz, and H. Weiss, Springer-Verlag, New York, 1982.

[6] D. Gerlich, "Elastic Constants of Single-Crystal Indium Arsenide," J. Appl. Phys., vol. 34 (9), pp. 2915-2919, Sep. 1963. DOI: http://doi. org/10.1063/1.1729833.

[7] M. Kocher, A. Jain, S. Ping-Ong, and G. Hautier, "Materials Project structure optimization". Available in: http://materialsproject.org/materials/mp-20305/.

[8] E. S. Penev, "On the theory of surface diffusion in InAs/GaAs (001) Heteroepitaxy," Technischen Universitat Berlin, 2002.

[9] S. W. Ellaway, and D. A. Faux, "On the elastic properties of InAs under hydrostatic pressure", Phys. Stat. Sol. (b)., vol. 235 (2), pp. 437-440, Feb. 2003. DOI: http://doi.org/10.1002/pssb.200301598.

[10] L. Louail, D. Maouche, and A. Hachemi, "Elastic properties of InAs under pressure up to $18 \mathrm{GPa}$," Mater. Lett., vol. 60 (27), pp. 3269-3271, Nov. 2006. DOI: http://doi.org/10.1016/j.matlet.2006.03.011.

[11] Ioffe Physical Technical Institute, "Semiconductors on NSM". Available in: http://www.ioffe.rssi.ru/ SVA/NSM/Semicond/.

[12] J. P. Perdew, and A. Zunger, "Self-interaction correction to density-functional approximations for many-electron systems," Phys. Rev. B., vol. 23, pp. 5048-5079, 1981. DOI: http://doi.org/10.1103/ PhysRevB.23.5048.

[13] J.P.Perdew, K. Burke, and M.Emzerhof, “Generalized Gradient Approximation Made Simple," Phys. Rev. Lett., vol. 77, pp. 3865-3868, Oct. 1996. DOI: http:// doi.org/10.1103/PhysRevLett.77.3865.

[14] P. E. Blochl, "Projector augmented-wave method," Phys. Rev. B., vol. 50, pp. 17953-17979, Dec. 1994. DOI: http://doi.org/10.1103/PhysRevB.50.17953.

[15] G. Kresse, and D. Joubert, "From ultrasoft pseudopotentials to the projector augmented wave method," Phys. Rev. B., vol. 59, pp. 17581775, Dec. 1999. DOI: http://doi.org/10.1103/ PhysRevB.59.1758.

[16] G. Kresse, and J. Furthmüller, "Efficiency of abinitio total energy calculations for metals and semiconductors using a plane-wave basis set," Comput. Mater. Sci., vol. 6, pp. 15-50, 1996. DOI: http://doi.org/10.1016/0927-0256(96)00008-0.

[17] G. Kresse, and J. Furthmüller, "Efficient iterative schemes for ab initio total energy calculations using a plane-wave basis set," Phys. Rev. B., vol. 54, pp. 11169-11186, 1996. DOI: http://doi.org/10.1103/ PhysRevB.54.11169.

[18] A. Otero-de-la-Roza, and V. Luaña, "Gibbs2: A new version of the quasi-harmonic model code. I. Robust treatment of the static data," Comput. Phys. Commun., vol. 182 (8), pp. 1708-1720, Aug. 2011. DOI: DOI: http://doi.org/10.1016/j.cpc.2011.04.016.

[19] A. Otero-de-la-Roza, and V. Luaña, "Equations of state and thermodynamics of solids using empirical corrections in the quasiharmonic approximation," Phys. Rev. B., vol. 84, pp. 184103(1)-184103(20), 2011.

[20] F. D. Murnaghan, "The compressibility of media under extreme pressures," Proc. Natl. Acad. Sci., vol. 30 (9), pp. 244-247, Sep. 1944. DOI: http://doi. org/10.1073/pnas.30.9.244.

[21] G. V. Ozolin'sh, G. K. Averkieva, A. F. Levin'sh, and N. A. Goryunova, "Investigation of Gallium and Indium Antimonides," Sov. Phys. Crystallogr., vol. 7, pp. 691, 1963.

[22] P. E. Van Camp, V. E. Van Doren, and J. T. Devreese, "Pressure dependence of the electronic properties of cubic III-V In compounds," Phys. Rev. B., vol. 41 (3), pp. 1598-1602, Jun. 1990. DOI: http://doi. org/10.1103/PhysRevB.41.1598.

[23] K. Yamaguchi, Y. Takeda, K. Kameda, and K. Itagaki, "Measurements of Heat of Formation of GaP, InP, GaAs, InAs, GaSb and InSb," Mater. Trans., JIM, vol. 35 (9), pp. 596-602, 1994. DOI: http://doi. org/10.2320/matertrans1989.35.596.

[24] S. Adachi, Properties of group-IV, III - V and II - VI semiconductors, John Wiley \& Sons Ltd, 2005. DOI: http://doi.org/10.1002/0470090340. 
[25] T. Uesugi, Y. Takigawa, and K. Higashi, "Elastic Constants of AlLi from First Principles," Mater. Trans., vol. 46 (6), pp. 1117-1121, 2005. DOI: http:// doi.org/10.2320/matertrans.46.1117.

[26] H. Fu, D. Li, F. Peng, T. Gao, and X. Cheng, "Ab initio calculations of elastic constants and thermodynamic properties of NiAl under high pressures," Comput. Mater. Sci., vol. 44 (2), pp. 774-778, Dec. 2008. DOI: http://doi.org/10.1016/j.commatsci.2008.05.026.

[27] R. Hill, "The Elastic Behaviour of a Crystalline Aggregate," Proc. Phys. Soc. A., vol. 65 (389), pp. 349-399, 1952. DOI: http://doi.org/10.1088/0370$1298 / 65 / 5 / 307$.

[28] L. O. Anderson, "A simplified method for calculating the debye temperature from elastic constants," J. Phys. Chem. Solids., vol. 24 (7), pp. 909-917, Jul. 1963. DOI: http://doi.org/10.1016/00223697(63)90067-2.

[29] K. Kuriyama, and S. Saito, "Elastic constants of single-crystal lithium indium," Phys. Rev. B., vol. 13 (4), pp. 1528-1531, Feb. 1976. DOI: http://doi. org/10.1103/PhysRevB.13.1528.

[30] K. Kuriyama, S. Saito, and K. Iwamura, "Ultrasonic study on the elastic moduli of the NaTl (B32) structure," J. Phys. Chem. Solids., vol. 40 (6), pp. 457461, Jan. 1979. DOI: http://doi.org/10.1016/00223697(79)90062-3.
[31] N. G. Einspruch, and R. J. Manning, "Elastic Constants of Compound Semiconductors $\mathrm{ZnS}, \mathrm{PbTe}$, GaSb," J. Acoust. Soc. Am., vol. 35 (2), pp. 215-216, Feb. 1963. DOI: http://doi.org/10.1121/1.1918434.

[32] H. M. Ayedh, and A. Wacker, "Acoustic Phonons in Nanowires with Embedded Heterostructures," J. Nanomater, vol. 2011, Article ID 743846, 2011. DOI: http://doi.org/10.1155/2011/743846.

[33] F. Tran, and P. Blaha, "Accurate band gaps of semiconductors and insulators with a semilocal exchange-correlation potential," Phys. Rev. Lett., vol. 102, pp. 226404 (4pp), 2009.

[34] A. Haddou, H. Khachai, R. Khenata, F. Litimein, A. Bouhemadou, G. Murtaza, Z. Alahmed, S. BinOmran, and B. Abbar, "Elastic, optoelectronic, and thermal properties of cubic $\mathrm{CSi}_{2} \mathrm{~N}_{4}$ : an ab initio study," J. Mater. Sci., vol. 48 (23), pp. 8235-8243, Dec. 2013. DOI: http://doi.org/10.1007/s10853013-7636-7.

[35] W. López-Pérez, P. Castro-Diago, L. RamírezMontes, A. González-García, and R. GonzálezHernández, "Effects of scandium composition on the structural, electronic, and thermodynamic properties of $\mathrm{SC}_{\mathrm{x}} \mathrm{Y}_{1-\mathrm{x}}$ metallic alloys," Philos. Mag, vol. 96 (5), pp. 498-510, Feb. 2016. DOI: http://doi.org/10.1080 /14786435.2016.1140915.

[36] C. Kittel, "Introduction to solid state physics," New York, John Wiley \& Sons, Inc., 7th ed., 1996. 